\title{
Quantitative Evaluation of the Regenerated Dura Mater in a Decompressive Skull Trepanation Model in Rats
}

\author{
Evaluación Cuantitativa de la Duramadre Regenerada en un \\ Modelo de Perforación Cranial Descompresiva en Ratas
}

\begin{abstract}
Panteleichuk Andrii B. ${ }^{1}$; Shmeleva Anna A. ${ }^{1}$; Kadzhaya Mykola V. ${ }^{1}$; Hnatiuk Olena P. Karakhim Sergiy I. ${ }^{3}$ Dovbeshko Galina I. ${ }^{2}$; Savosko Serhii I. ${ }^{4} \&$ Kozakevych Roman B. ${ }^{5}$
\end{abstract}

PANTELEICHUK, A. B.; SHMELEVA, A. A.; KADZHAYA, M. V.; HNATIUK, O. P.; KARAKHIM, S. I.; DOVBESHKO, G. I.; SAVOSKO, S. I. \& KOZAKEVYCH, R. B. Quantitative evaluation of the regenerated dura mater in a decompressive skull trepanation model in rats. Int. J. Morphol., 39(6):1731-1736, 2021.

SUMMARY: Regeneration of the dura mater following duraplasty using a collagen film, a chitosan film, or a combination of both with gelatin, was studied in a craniotomy and penetrating brain injury model in rats. Collagen autofluorescence in the regenerated dura mater was evaluated using confocal microscopy with excitation at $\lambda \mathrm{em}=488 \mathrm{~nm}$ and $\lambda \mathrm{em}=543 \mathrm{~nm}$. An increase in regeneration of the extracellular matrix of connective tissue and an increase in matrix fluorescence were detected at 6 weeks after duraplasty. The major contributors to dura mater regeneration were collagen films, chitosan plus gelatin-based films, and, to a much lesser extent, chitosan-based films. By using autofluorescence densitometry of extracellular matrix, the authors were able to quantify the degree of connective tissue regeneration in the dura mater following duraplasty.

KEY WORDS: Dura mater; Duraplasty; Fluorescence; Densitometry.

\section{INTRODUCTION}

The problem of duraplasty is still the subject of many scientific controversies and unresolved practical problems. Is duraplasty with restoration of subdural space tightness mandatory? Is such an operation always possible using only autologous tissues? Which dura mater substitute is the best? There is no unambiguous answer to these and other questions, as evidenced by numerous scientific publications on the issue of duraplasty. Thus, it is obvious that the search for an ideal dural substitute continues (Schmalz et al., 2018). Widespread use of autologous tissues (femoral fascia, temporal fascia, etc.) is gradually declining in favor of artificially created film materials. Among such materials the most interesting are those that have the biodegradation ability: temporarily assuming the function of damaged dura mater, as a result of surgery or injury, they are gradually resorbed and replaced by newly formed connective tissue. Film materials based on natural biopolymers - collagen and chitosan are the most promising for the creation of such artificial substitutes for dura mater (Chalonglarp et al., 2006; Zerris et al., 2007; Chiono et al., 2008).

The dura mater is a strong membrane that lines the inside of the skull and creates four septa. The mechanical functions of the dura mater are as follows: to be a protective membrane for the brain, separating the brain (which pulsates) from the skull bones; transfer mechanical stress from one bone to another; reduce pressure waves in the cerebrospinal fluid by compartmentalizing the cranial cavity (Wilcox et al., 2003). It consists mainly of collagen fibers, which are organized in bundles; it is believed that this structure contributes to the overall strength of the skull wall (Panteleichuk et al., 2019, 2020). Thus, the study of the structural repair of the dura mater is crucial for assessing the success of duraplasty.

\footnotetext{
${ }^{1}$ The State Institution Romodanov Neurosurgery Institute National Academy of Medical Sciences of Ukraine, Kyiv, Ukraine.

${ }^{2}$ Department of Physics of Biological Systems, Institute of Physics, Natl. Acad. of Sci. of Ukraine, Kyiv, Ukraine.

${ }^{3}$ Palladin Institute of Biochemistry of the National Academy of Sciences of Ukraine, Kyiv, Ukraine.

${ }^{4}$ Department of Histology and Embryology, Bogomolets National Medical University, Kyiv, Ukraine.

${ }^{5}$ Chuiko Institute of Surface Chemistry, National Academy of Sciences of Ukraine.
} 
The aim of this study is to quantify the extracellular matrix $(\mathrm{ECM})$ in the regenerative dura matter in peri-implant area in rat model of decompressive skull trepanation.

\section{MATERIAL AND METHOD}

Craniotomy and penetrating brain injury were induced in male rats (aged 12 months, weighing 250 to $300 \mathrm{~g}$ ) (Purushothuman et al., 2013). The surgery was performed under general anesthesia by an intramuscular injection of xylazine solution (Sedazin, Biowet, Poland, $15 \mathrm{mg} / \mathrm{kg}$ ) and ketamine (Calypsol, Gedeon Richter, Hungary, $70 \mathrm{mg} / \mathrm{kg}$ ). After shaving and disinfecting the head with $10 \%$ Betadine solution (Betadine, Egis, Hungary), an incision was made along the midline to expose the cranial roof bones. A burr hole $4 \times 7 \mathrm{~mm}$ in size was created in the right parietal area using a high-speed drill. The bone flap was separated from the underlying dura mater and removed. An X-shaped dissection of the dura mater was made carefully from the center of the hole towards its edges. The brain surface was exposed and the cerebral cortex was penetrated with a G18 needle to a depth of $2 \mathrm{~mm}$, thus inducing a model of traumatic brain injury with focal hemorrhage. Then, autologous duraplasty or synthetic film duraplasty was performed. The bone flap was not returned to its original position, i.e. a decompressive skull trepanation was created.

The operated rats were divided into the following groups:

1 - autologous duraplasty - the flaps of dura mater were returned to their original position without suturing, forming a diastasis between the margins;

2 - collagen duraplasty - a collagen film was placed onto the trephine defect;

3 - chitosan film duraplasty - a chitosan-based film was placed onto the trephine defect;

4 - collagen-gelatin duraplasty - a collagen film topped with a gelatin-based film were placed onto the trephine defect;

5 - chitosan-gelatin duraplasty - a chitosan-based film topped with a gelatin-based film were placed onto the trephine defect.

All films were cut according to the trephine defect size and irrigated with normal saline. We used collagen films that were based on natural equine collagen (180 to $200-\mu \mathrm{m}$ thick) as described in (Knopp et al., 2005), with the exception that we did not use any additional glue (fibrin glue, etc.). Chitosan- and gelatin-based films $(0.025$ and $0.30-\mathrm{mm}$ thick, respectively) were made in the Chuiko Institute of Surface Chemistry (Kyiv, Ukraine).
The bone flap was not returned to its original position following the artificial restoration of the dura mater. After ensuring hemostasis, the wound was closed with Vicryl 5-0 sutures (Ethicon, USA) and treated with Povidone-Iodine solution (EGIS Pharmaceuticals, PLC, Hungary). The animals received antibiotic prophylaxis with cephalosporins $(20 \mathrm{mg} / \mathrm{kg}$ intramuscularly). The animals were sacrificed after 6 weeks by decapitation under anesthesia with $0.1 \%$ ketamine $(2.0 \mathrm{ml})$.

After the animals were sacrificed, the implanted films together with the brain were fixed as a single block in neutral formalin solution (5-7-10\% in a sequential order, for 24 hours), dehydrated in ethanol and toluene, and embedded in paraffin wax (Thermo Scientific RichardAllan Scientific, Paraffin type 6 REE 8336, Kalamazoo, USA). Using a HM430 microtome (Microm, Germany), 7-mm thick tissue slices were obtained. The slices were stained with hematoxylin and eosin (H\&E) and mounted in the mounting media (Thermo Scientific Richard-Allan Scientific Cytoseal 60, REF 8310-16, Kalamazoo, USA). The microscope slides were studied under an Axiophot microscope (Carl Zeiss, Germany).

Autofluorescence was evaluated using a Carl Zeiss LSM-510 META confocal microscope (Carl Zeiss, Germany) with Plan-Neofluar 40x/0.6 Korr lenses and a Zeiss AxioCam camera. Fluorescent images were obtained by excitation with a UV HBO 100 lamp with green (Fset10 wf) and red (Fset20 wf) filters, as well as by a laser excitation at wavelengths of $488 \mathrm{~nm}$ (Green) and $543 \mathrm{~nm}$ (Red). Images were split into channels (based on excitation by lasers at respective wavelengths) and atemplate was created using the Zeiss LSM Image Version 4.0.0.241 software (Carl Zeiss MicroImaging GmbH, Germany).

Images obtained after laser excitation at $488 \mathrm{~nm}$ (Green) and $543 \mathrm{~nm}$ (Red) were assessed using ImageJ 2.2.0/1.53c; 64-bit Java 1.8.0_172 software. The subsequent mathematical and statistical operations were performed on the mean gray value, which corresponds to integrated density per study area. Study limitation: Erythrocytes exhibit strong autofluorescence which confounds the evaluation of the parameter in large areas; therefore, prior to measurements, erythrocytes were removed from images in ImageJ by a "freehand selection" and delete function.

Statistical studies were carried out using one-way ANOVA with Bonferroni post hoc analysis and MannWhitney U-test. Statistical analysis of the results was conducted with the StatPlus 5.9.9.4/Core v6.7.3 software (AnalystSoft Inc., USA). 
Bioethics. The surgical part of the experiment and the withdrawal of animals from the experiment was provided in accordance with the bioethics as regulated by Council Directive 2010/63 / EC " On the protection of animals used for scientific purposes " (1986) and the Law of Ukraine No. 3447-IV "On the Protection of Animals from Cruel Treatment" (2006). The study was approved by the Committee on Bioethics of "The State Institution Romodanov Neurosurgery Institute National Academy of Medical Sciences of Ukraine" (Minutes N ${ }^{\circ} 18$ of June 10, 2016).

\section{RESULTS}

Autologous duraplasty showed fusion in the peripheral portion of the trephine defect, between the bone margins and the dura mater surface, and scarring directly in the lumen of the trephine window. No residual film was found in groups with films based on collagen, chitosan, or a combination of both with gelatin. The dura mater surface within and outside of the trepanation area did not differ. Fusion was observed in the peripheral portion of the bone window, and no fusion was seen in the lumen of the trephine window. Scar tissue formations in the lumen of the trephine window were observed in the collagen plus gelatin group.

Microscope slides stained with $\mathrm{H} \& \mathrm{E}$ showed the formation of connective tissue (multi-directional bundles of collagen fibers, fibroblasts and fibrocytes) andisolated regenerated microvessels following autologous duraplasty, which is a marker of active regeneration. A greater density of ECM fibers was observed in the collagen and chitosan plus gelatin groups. This is seen particularly clearly on a fluorescent image (laser excitation at $\lambda \mathrm{em}=488 \mathrm{~nm}$ ). Both groups had considerably higher collagen density compared to the autologous duraplasty group, while the collagen plus gelatin group showed no significant increase in collagen density and no active angiogenesis. It can be assumed that gelatin in this case slows down the healing process; however, autofluorescence with laser excitation at $\lambda \mathrm{em}=543 \mathrm{~nm}$ was

Table I. Mean fluorescence of ECM in dura mater after various types of duraplasty.

\begin{tabular}{llc}
\hline \multirow{2}{*}{ Group } & \multicolumn{2}{c}{ Wavelength } \\
\cline { 2 - 3 } & $\lambda_{\mathrm{em}}=488$ (green) & $\lambda_{\mathrm{e}_{\mathrm{m}}}=543$ (red) \\
\hline Autologous duraplasty & $17.3 \pm 0.64$ & $3.3 \pm 0.04$ \\
Collagen film & $36.7 \pm 0.59^{*}$ & $32.3 \pm 4.5^{*}$ \\
Chitosan film & $12.9 \pm 0.07$ & $3.0 \pm 0.16$ \\
Collagen film + gelatin film & $15.4 \pm 2.27^{* *}$ & $9.4 \pm 2.86^{*}, * *$ \\
Chitosan film + gelatin film & $30.9 \pm 3.59^{* \wedge}$ & $12.9 \pm 4.0^{*}$ \\
\hline
\end{tabular}

*P $\leq 0.05$ compare with autologous duraplasty; ** $\mathrm{P}<0.05$ compare with collagen duraplasty; ^ $\mathrm{P} \leq 0.05$ compare with collagen-gelatin duraplasty increased. Microscope slides stained with H\&E contained many fibroblasts and thin fibers. There was no significant difference between regenerated tissues around the autologous dura mater and the chitosan film. There was no significant difference in the healing process.

The values of the ECM fluorescence intensity in regenerated dura mater are shown in Table I. A significantly higher fluorescence intensity was observed in the collagen and chitosan plus gelatin groups with laser excitations at $\lambda \mathrm{em}=488 \mathrm{~nm}$ and $\lambda \mathrm{em}=543 \mathrm{~nm}$ (after the second laser excitation, the intensity in the collagen film group was higher) and in the collagen plus gelatin group with excitation at $\lambda \mathrm{em}=543 \mathrm{~nm}$. In summary, the application of the collagen film contributed to dura mater healing to a greater extent compared to other films by activating connective tissue regeneration and the synthesis of collagen into the ECM, and the implanted film degraded by week 6 (Fig. 1).

\section{DISCUSSION}

Connective tissue is the main component of the dura mater, which is why studying tissue healing in the periimplant area remains relevant. The strain in the dura mater and the fibrous connective tissue regeneration are characterized by the formation of numerous collagen fibers (Maikos et al., 2008). To date, a number of devitalized or synthetic duraplasty films that can close a defect and promote regeneration of the dura mater connective tissue have been developed. Despite being composed of collagen, the collagen films derived from bovine pericardium, dermis, and Achilles tendon all have differences associated with their mechanical and physical properties, low solubility, and porosity, which may affect the ECM remodeling in the regenerated dura mater (Zerris et al.). Chitosan is a biocompatible non-toxic polymer which is structurally similar to chitin and biodegradable to $\mathrm{N}$-acetylglucosamine or glucosamine in tissues. It promotes cell adhesion and has wound-healing and hemostatic effects (Guibal, 2005). Human connective tissues do not contain chitosan but show a structural similarity to glycosaminoglycans (GAG), which are the main components of the ECM. This brings up the question of what is the most efficient material in terms of dura mater regeneration. In this paper, we addressed the regeneration of dura mater using films based on collagen, chitosan, and the combination of both with gelatin.

Quantification of dura mater healing after duraplasty is a challenging task. There 


\section{$\mathbf{H \& E}$}
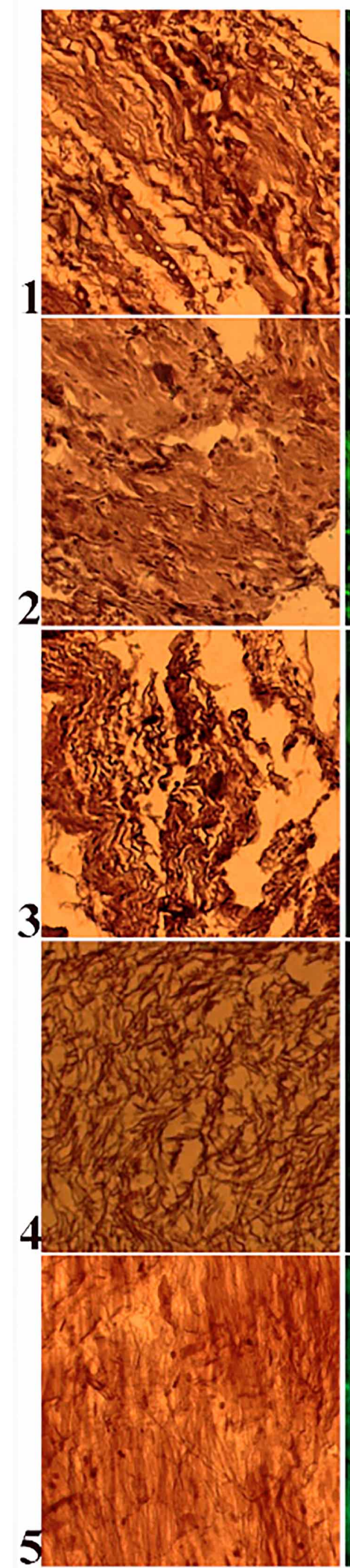

$\lambda_{\mathrm{em}}=\mathbf{4 8 8}$
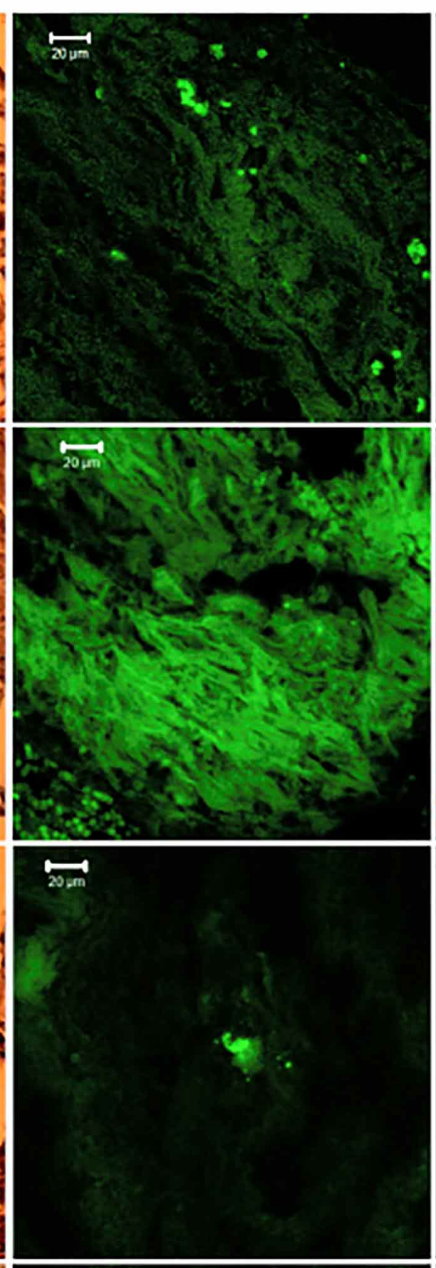

$\stackrel{20 \mathrm{rm}}{\longrightarrow}$

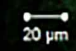

Mest $\lambda_{\mathrm{em}}=\mathbf{5 4 3}$

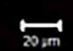

$\stackrel{\leftrightarrow}{20 \mathrm{~m}}$

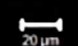

$\stackrel{\mapsto}{20 \mathrm{~mm}}$

\section{$\longrightarrow$}
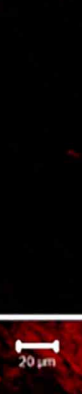

$\stackrel{20 \mathrm{rm}}{2}$

20
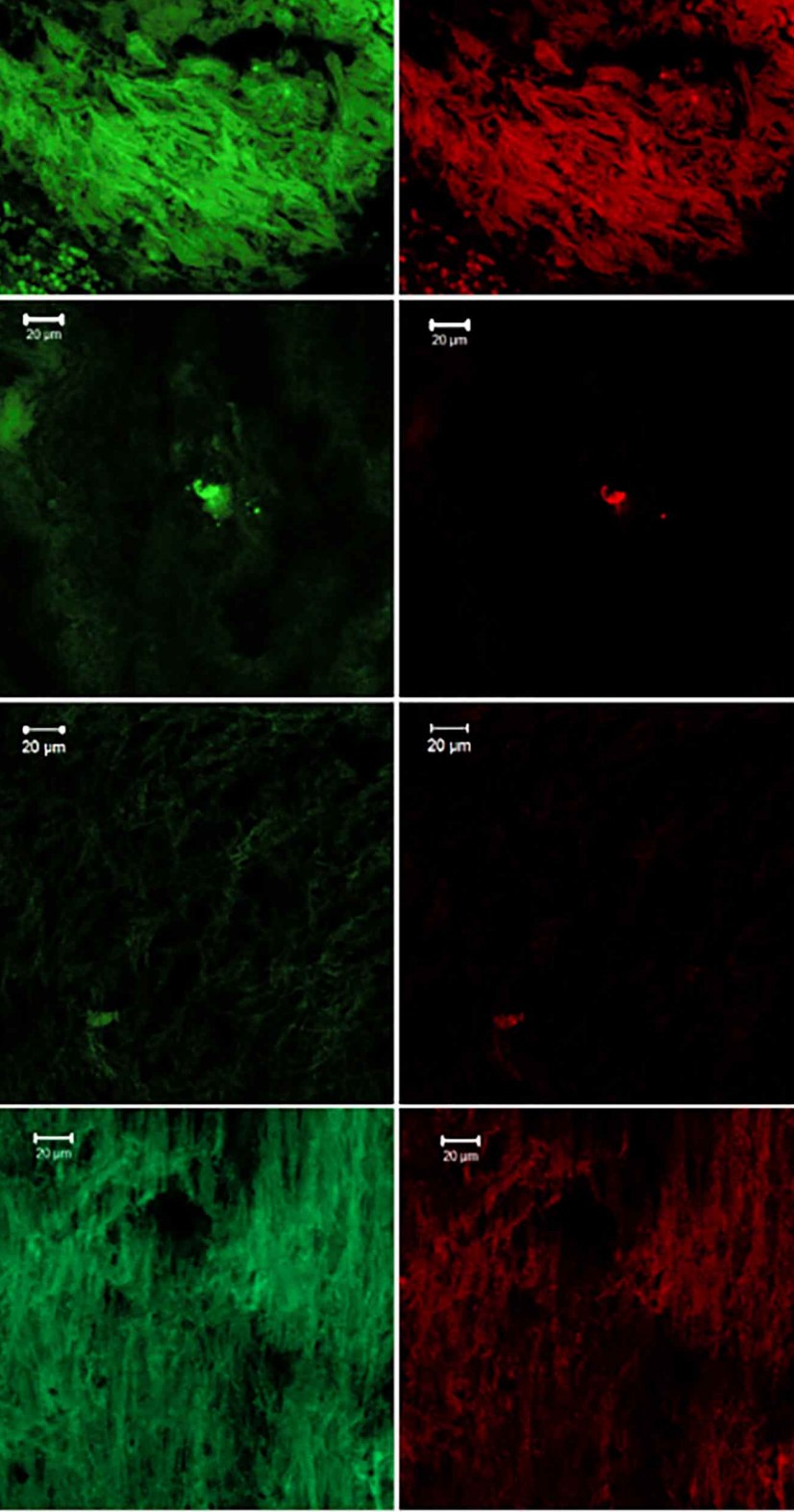

are limitations to the use of image processing software for microscope slides stained using routine techniques, such as $\mathrm{H} \& \mathrm{E}$, and more specific collagen staining techniques, e.g., Masson's trichrome stain, are often associated with staining standardization errors (Flores et al., 2021), and overlapping absorption spectra of the dyes create problems with color deconvolution, which, in turn, may lead to inadequate biomarker identification (Gibbs et al., 2015), thus rendering the results invalid. On the contrary, fluorescent microscopy with emission light filters allows splitting of signals with various wavelengths, which considerably increases the capabilities of digital image processing. The above challenges may be addressed by inducing collagen autofluorescence in microscope slides with subsequent evaluation using the appropriate software (Caorsi et al., 2013). In our study, this was achieved by confocal microscopy.

Fig. 1. Microimages of regenerated rat dura mater 6 weeks after various types of duraplasty. Tissue slices stained by $\mathrm{H} \& \mathrm{E}$ and excited with a laser at $\lambda \mathrm{em}=488 \mathrm{~nm}$ and $\lambda$ em $=543 \mathrm{~nm}$. Note: $1-$ autologous duraplasty; 2 collagen film; 3 - chitosan film; 4 - collagen film with gelatin; 5 - chitosan film with gelatin. Scale bar $20 \mu \mathrm{m}$. 
Eosin is known to be strongly fluorescent. Certain characteristics of eosin fluorescence have been established. For instance, the absorption band of eosin lies in the range of 450 to $550 \mathrm{~nm}$ with a peak at $525 \mathrm{~nm}$. In addition, eosin exhibits a strong fluorescence band with a peak at $570 \mathrm{~nm}$ (Gibbs et al.). When excited at $\lambda=380 \mathrm{~nm}$, eosin Y emits maximum radiation at $580 \mathrm{~nm}$, and when the concentration of eosin $\mathrm{Y}$ in a solution increases, the fluorescence becomes more intense, with a gradual shift to higher wavelengths up to $600 \mathrm{~nm}$ (Ali et al., 2017). Excitation of hematoxylin at $\lambda=280 \mathrm{~nm}$ also produces a shoulder of $320 \mathrm{~nm}$ in its radiation spectra, a short shoulder at $590 \mathrm{~nm}$, and a fulllength spectrum at $660 \mathrm{~nm}$. Examination of microscope slides stained with $\mathrm{H} \& \mathrm{E}$ under a fluorescence microscope shows selective bright-green or red radiation of eosinophilic structures under blue $(490 \mathrm{~nm})$ or green $(545 \mathrm{~nm})$ irradiation. Examination of tissue sections (skin, kidney, lung) stained with H\&E under a fluorescence microscope (green/blue and yellow filter) was sensitive enough to determine the specific location of elastic fibers and collagen in the ECM (Heo \& Song, 2011). When non-stained and stained slices of pericardium, dura mater and skin grafts were subjected to excitation at 510 to $560 \mathrm{~nm}$, bright-red fluorescence was detected under confocal microscope (Makarov et al., 2017). The results were comparable to the findings obtained with differential staining techniques, such as Weigert's stain and Masson's trichrome stain, and the authors concluded that this selective fluorescence in H\& E-stained areas was attributable to eosin only, and differential staining techniques can be replaced with fluorescence microscopy. Additional staining with hematoxylin reduces the excessive fluorescence of eosin and alters image contrasting (Heo \& Song). Although hematoxylin is characterized by a wide absorption band in the $400-700 \mathrm{~nm}$ range with a peak at $570 \mathrm{~nm}$, it does not exhibit autofluorescence.

In addition, ECM in tissues exhibits more intense autofluorescence compared to cellular components because collagen and elastin have high quantum yields (Deeb et al., 2008).

In this study, we have conducted a number of experiments with various excitation wavelengths, and eventually selected laser excitation at wavelengths of 408, 488 and $543 \mathrm{~nm}$ to demonstrate the physical origin of the signal in H\&E-stained microscope slides (laser excitation data at $\lambda=405 \mathrm{~nm}$ are not shown here because the findings (emission) were insignificant). Regenerated dura mater emitted bright-green and less intense red radiation after laser excitation at $488 \mathrm{~nm}$ and $543 \mathrm{~nm}$, respectively. This allowed us to quantify the apparent density of the ECM that regenerated after duraplasty. Our findings have shown that the major contributors to dura mater regeneration were collagen films, chitosan plus gelatin-based films, and, to a much lesser extent, chitosan-based films. However, the healing process over 6 weeks after duraplasty was slower with collagen plus gelatin films than with collagen-only films. This can be attributed to a longer duration of the implanted film biodegradation process, if only because we used twice as many films (two films instead of one). The connective tissue density in the peri-implant area has increased and was similar to scar tissue density. However, we do not exclude the possibility that the dura mater regeneration could reach a sufficient degree with a longer observation period.

The use of autofluorescence in H\&E-stained sections has proved to be a faster and more cost-effective technique than immunohistochemical detection of certain ECM components (Jakubovsky et al., 2002). Fluorescence persists for years after specimen preparation. Despite method limitations, such as erythrocyte autofluorescence, which makes it impossible to obtain a high-quality and specific ECM image, the software allows the erythrocytes to be removed from the image (the area value will be equal to 0 or will not be included in calculations during the selective assessment of the regions of interest, and this will have negligible to no effect on the quantification results). It was concluded that autofluorescence-based analytical techniques in light microscopy are superior to visual and semiquantitative methods when evaluating the ECM density.

PANTELEICHUK, A. B.; SHMELEVA, A. A.; KADZHAYA, M. V.; HNATIUK, O. P.; KARAKHIM, S. I.; DOVBESHKO, G. I.; SAVOSKO, S. I. \& KOZAKEVYCH, R. B. Evaluación cuantitativa de la duramadre regenerada en un modelo de perforación cranial descompresiva en ratas. Int. J. Morphol., 39(6):17311736, 2021

RESUMEN: Se estudió la regeneración de la duramadre después de una duraplastía utilizando una lámina de colágeno, una lamina de quitosano o una combinación de ambas con gelatina en un modelo de craneotomía y lesión cerebral en ratas. La autofluorescencia del colágeno en la duramadre regenerada se evaluó mediante microscopía confocal con excitación a $\lambda$ em $=488 \mathrm{~nm}$ y $\lambda \mathrm{em}=543 \mathrm{~nm}$. Se observó un aumento en la regeneración de la matriz extracelular del tejido conectivo y un aumento en la fluorescencia de la matriz a las 6 semanas después de la duraplastía. Se observe un efecto significativo en la regeneración de la duramadre con las láminas de colágeno, las láminas en base de quitosano más gelatina y, en un menor grado, las láminas a base de quitosano. Mediante el uso de densitometría de autofluorescencia de la matriz extracelular, los autores lograron cuantificar el grado de regeneración del tejido conectivo en la duramadre después de la duraplastía.

PALABRAS CLAVE: Duramadre; Duraplastía; Fluorescencia; Densitometría. 


\section{REFERENCES}

Ali, H.; Ali, S.; Mazhar, M.; Ali, A,; Jahan, A. \& Ali, A. Eosin fluorescence: A diagnostic tool for quantification of liver injury. Photodiagnosis Photodyn. Ther, 19:37-44, 2017.

Caorsi, V.; Toepfer, C.; Sikkel, M. B.; Lyon, A. R.; MacLeod, K. \& Ferenczi, M. A. Non-linear optical microscopy sheds light on cardiovascular disease. PLoS One, 8(2):e56136, 2013.

Chalonglarp, T.; Sorada, K. \& Neeracha, S. Properties of collagen/chitosan scaffolds for skin tissue engineering. J. Met. Mater. Miner., 16:37-44, 2006.

Chiono, V.; Pulieri, E. \& Vozzi, G. Genipin-crosslined chitosan/gelatin blends for biomedical applications. J. Mater. Sci. Mater. Med., 19:88998, 2008.

Deeb, S.; Nesr, K. H.; Mahdy, E.; Badawey, M. \& Badei, M. Autofluorescence of routinely hematoxylin and eosin stained sections without exogenous markers. Afr. J. Biotechnol., 7(5):504-7, 2008.

Flores, V.; Venegas, B.; Donoso, W.; Ulloa, C.; Chaparro, A.; Sousa, V. \& Beltrán, V. Collagen quantification in peri-implant soft tissues in human peri-implantitis lesions. Int. J. Morphol., 39(3):683-7, 2021.

Gibbs, S. L.; Genega, E.; Salemi, J.; Kianzad, V.; Goodwill, H. L.; Xie, Y.; Oketokoun, R.; Khurd, P.; Kamen, A. \& Frangioni, J. V. Near-infrared fluorescent digital pathology for the automation of disease diagnosis and biomarker assessment. Mol. Imaging, 14(0):1-9, 2015.

Guibal, E. Heterogeneous catalysis on chitosan-based materials: a review. Prog. Polym. Sci., 30(1):71-109, 2005.

Heo, Y. S. \& Song, H. J. Characterizing cutaneous elastic fibers by eosin fluorescence detected by fluorescence microscopy. Ann. Dermatol., 23(1):44-52, 2011.

Jakubovsky, J.; Guller, L.; Cerná, M.; Balázová, K.; Polák, S.; Jakubovská, V. \& Babál, P. Fluorescence of hematoxylin and eosin-stained histological sections of the human spleen. Acta Histochem., 104(4):3536, 2002.

Knopp, U.; Christmann, F.; Reusche, E. \& Sepehrnia, A. A new collagen biomatrix of equine origin versus a cadaveric dura graft for the repair of dural defects--a comparative animal experimental study. Acta Neurochir. (Wien), 147(8):877-87, 2005.

Maikos, J. T.; Elias, R. A. \& Shreiber, D. I. Mechanical properties of dura mater from the rat brain and spinal cord. J. Neurotrauma, 25(1):38-51, 2008.

Makarov, M. S.; Storozheva, M. V. \& Borovkova, N. V. Collagen fiber autofluorescence level in evaluating the biological properties of tissue grafts. Sovrem. Tehnol. Med., 9(2):83-90, 2017.

Panteleichuk, A.; Kadzhaya, M.; Biloschytsky, V.; Shmeleva, A.; Petriv, T.; Gnatyuk, O.; Dovbeshko, G.; Kozakevych, R. \& Tyortyh, V. Composite chitosan/polyethylene oxide film for duraplasty in traumatic brain injury model in rats. Cell Organ Transplantology, 8(1):26-31, 2020.

Panteleichuk, A.; Kadzhaya, N. V.; Shmeleva, A. A.; Malysheva, T. A.; Gnatyuk, O. P. \& Dovbeshko, G. I. Theoretical substantiation of the efficiency of biopolymers application in experimental TBI (literature review and own results). Ukr. Neurosurg. J., 25(4):64-71, 2019.

Purushothuman, S.; Marotte, L.; Stowe, S.; Johnstone, D. M. \& Stone, J. The response of cerebral cortex to haemorrhagic damage: experimental evidence from a penetrating injury model. PLoS One, 8(3):e59740, 2013.

Schmalz, P.; Griessenauer, C.; Ogilvy, C. S.; Thomas, A. J. \& Schmalz, P. Use of an absorbable synthetic polymer dural substitute for repair of dural defects: a technical note. Cureus, 10(1):e2127, 2018.

Wilcox, R. K.; Bilston, L. E.; Barton, D. C. \& Hall, R. M. Mathematical model for the viscoelastic properties of dura mater. J. Orthop. Sci., 8(3):432-4, 2003

Zerris, V. A.; James, K. S. \& Roberts, J. B. Repair of the dura mater with processed collagen devices. J. Biomed. Mater. Res. B Appl. Biomater. 83(2):580-8, 2007.
Corresponding author:

Andrii Panteleichuk

The State Institution Romodanov Neurosurgery Institute

National Academy of Medical Sciences of Ukraine

32 Platona Mayborody Str.

04050, Kyiv

UKRAINE

E-mail: basirovich@ukr.net

Received: 23-07-2021

Accepted: 25-08-2021 